\title{
Enthesitis-Related Arthritis
}

National Cancer Institute

\section{Source}

National Cancer Institute. Enthesitis-Related Arthritis. NCI Thesaurus. Code C119024.

A category of juvenile idiopathic arthritis associated with arthritis and enthesitis, which may involve the axial skeleton. It is a form of juvenile spondyloarthritis. 